\title{
INTRODUCTION \\ Neurosurgical management of stroke, organization of stroke management, and artificial intelligence applications
}

\author{
Elad I. Levy, MD, MBA, ${ }^{1}$ Philipp Taussky, MD, ${ }^{2}$ Jose E. Cohen, MD, ${ }^{3}$ and Peter Kan, MD, MPH ${ }^{4}$ \\ 'Departments of Neurosurgery and Radiology, Jacobs School of Medicine and Biomedical Sciences, University at Buffalo, \\ New York; '2Department of Neurosurgery, University of Utah, Salt Lake City, Utah; ${ }^{3}$ Department of Neurosurgery and Radiology, \\ Hadassah University Medical Center, Jerusalem, Israel; and ${ }^{4}$ Department of Neurosurgery, University of Texas Medical Branch, \\ Galveston, Texas
}

A CUTE ischemic stroke (AIS) remains a significant cause of death and disability in the United States. ${ }^{1}$ Among patients with AIS, the prevalence of large-vessel occlusion (LVO) approaches $20 \% .^{2}$ Since the publication of multiple randomized controlled trials in both early and late therapeutic time windows, ${ }^{3-9}$ mechanical thrombectomy (MT) has become the standard of care for select patients with LVO. With the rapid increase in the volume of MTs performed, it has become an important part of acute neurosurgical management, especially among endovascular neurosurgeons. As we expand the indications for MT, important questions that need to be answered include the need for concomitant intravenous thrombolysis with MT and the benefits of MT in patients with more distal occlusions, larger-core infarcts, and LVO in the posterior circulation.

As more patients are eligible for MT, the system of care must evolve to meet the demand. The ultimate goal of stroke network organization is to improve workflow so that appropriate patients with LVO can access thrombectomycapable centers with minimal delay because every hour of delay to reperfusion is associated with a $20 \%$ reduction in an independent functional outcome..$^{10} \mathrm{~A}$ Comprehensive Stroke Center is the current standard. Other innovative models being explored include mobile stroke units (ambulances with a CT scanner designed to perform prehospital intravenous thrombolysis) ${ }^{11}$ and mobile stroke teams (the treatment team travels to the local hospital where the patient presents). ${ }^{12}$

Finally, the integration of artificial intelligence into the standard workflow is crucial to further reduce the time to treatment. Automated software for diagnosis and patient selection for LVO exists and is used routinely in clinical practice. ${ }^{13}$

In this issue, the authors share data shaping the most current practice for MT. In addition, they describe technological advances designed to enhance patient access, workflow, and outcomes.

https://thejns.org/doi/abs/10.3171/2021.4.FOCUS21264

\section{References}

1. Stroke facts. CDC.gov. March 17, 2021. Accessed May 10, 2021. https://www.cdc.gov/stroke/facts.htm

2. Waqas M, Mokin M, Primiani CT, et al. Large vessel occlusion in acute ischemic stroke patients: a dual-center estimate based on a broad definition of occlusion site. J Stroke Cerebrovasc Dis. 2020;29(2):104504.

3. Berkhemer OA, Fransen PSS, Beumer D, et al. A randomized trial of intraarterial treatment for acute ischemic stroke. $N$ Engl J Med. 2015;372(1):11-20.

4. Saver JL, Goyal M, Bonafe A, et al. Stent-retriever thrombectomy after intravenous t-PA vs. t-PA alone in stroke. $N$ Engl $J$ Med. 2015;372(24):2285-2295.

5. Jovin TG, Chamorro A, Cobo E, et al. Thrombectomy within 8 hours after symptom onset in ischemic stroke. $N$ Engl J Med. 2015;372(24):2296-2306.

6. Goyal M, Demchuk AM, Menon BK, et al. Randomized assessment of rapid endovascular treatment of ischemic stroke. N Engl J Med. 2015;372(11):1019-1030.

7. Campbell BCV, Mitchell PJ, Kleinig TJ, et al. Endovascular therapy for ischemic stroke with perfusion-imaging selection. N Engl J Med. 2015;372(11):1009-1018.

8. Nogueira RG, Jadhav AP, Haussen DC, et al. Thrombectomy 6 to 24 hours after stroke with a mismatch between deficit and infarct. N Engl J Med. 2018;378(1):11-21.

9. Albers GW, Marks MP, Kemp S, et al. Thrombectomy for stroke at 6 to 16 hours with selection by perfusion imaging. $N$ Engl J Med. 2018;378(8):708-718.

10. Saver JL, Goyal M, van der Lugt A, et al. Time to treatment with endovascular thrombectomy and outcomes from ischemic stroke: a meta-analysis. JAMA. 2016;316(12):1279-1288.

11. Ebinger M, Siegerink B, Kunz A, et al. Association between 
dispatch of mobile stroke units and functional outcomes among patients with acute ischemic stroke in Berlin. JAMA. 2021;325(5):454-466.

12. Morey JR, Oxley TJ, Wei D, et al. Mobile interventional stroke team model improves early outcomes in large vessel occlusion stroke: the NYC MIST Trial. Stroke. 2020;51(12):3495-3503.

13. Rava RA, Peterson BA, Seymour SE, et al. Validation of an artificial intelligence-driven large vessel occlusion detection algorithm for acute ischemic stroke patients. Neuroradiol J. Published online March 3, 2021. doi:10.1177/1971400921998952

\section{Disclosures}

Dr. Levy has shareholder/ownership interests in NeXtGen Biologics, RAPID Medical, Claret Medical, Cognition Medical, Imperative Care (formerly the Stroke Project), Rebound Therapeutics, StimMed, and Three Rivers Medical; is a national principal investigator/on the steering committees of Medtronic (merged with Covidien Neurovascular) SWIFT Prime and SWIFT Direct Trials; receives honoraria from Medtronic (training and lectures); is a consultant for Claret Medical, GLG Consulting, Guidepoint Global, Imperative Care, Medtronic, Rebound, and StimMed; is on the advisory board of Stryker (AIS Clinical Advisory Board), NeXtGen Biologics, MEDX, Cognition Medical, and Endostream Medical; and is the site principal investigator for the CONFIDENCE study (MicroVention) and STRATIS Study-Sub I (Medtronic). Dr. Taussky is a consultant for Medtronic, Cerenovus, and Stryker.

\section{Correspondence}

Elad I. Levy: elevy@ubns.com. 